See Article page e513.

\section{Commentary: In the company of (gentle) men}

\author{
Stephanie Fuller, MD, MS
}

The results of a comprehensive survey completed by nearly all nationally trained and employed female congenital heart surgeons (CHSs) are not surprising. The survey collates their experiences and illustrates how bias and harassment may encumber a successful and productive career. Sinha and colleagues ${ }^{1}$ acknowledge that this effect is modifiable by the participation of unbiased leaders who generate and mandate institutional and behavioral change as our moral imperative.

In this timely analysis by Sinha and colleagues, ${ }^{1}$ the majority $(65 \%)$ of female CHSs, all of whom are Board certified by the American Board of Thoracic Surgery, more than half of whom report more than a decade in postgraduate training, and nearly half of whom possess advanced degrees, reported bias, discrimination, and sexual harassment.

Gender harassment includes verbal and nonverbal behaviors that convey hostility, objectification, and exclusion or second-class status of women. In medicine, this behavior is directly linked to attrition and the inability of women to secure leadership roles. ${ }^{2}$ One can argue that it is difficult to ascertain whether or not self-reported and perceived challenges, including the need to work harder, the lack of leadership opportunities, faltering confidence levels of cardiologists to female heart surgeons, and employability are potentially exaggerated by a minority group. However, these findings are corroborated by ample data in this article and beyond.

Sinha and colleagues ${ }^{1}$ identify several factors potentially prohibiting the advancement of women in CHS and remind us of the necessary actions to ensure

\footnotetext{
From the Division of Cardiothoracic Surgery, Children's Hospital of Philadelphia, Philadelphia, $\mathrm{Pa}$.

Disclosures: Dr Fuller is a consultant for W.L. Gore.

The Journal policy requires editors and reviewers to disclose conflicts of interest and to decline handling or reviewing manuscripts for which they may have a conflict of interest. The editors and reviewers of this article have no conflicts of interest.

Received for publication Oct 10, 2021; revisions received Oct 10, 2021; accepted for publication Oct 13, 2021; available ahead of print Oct 20, 2021.

Address for reprints: Stephanie Fuller, MD, MS, Division of Cardiothoracic Surgery, Children's Hospital of Philadelphia, 3401 Civic Center Blvd, Suite M875, Philadelphia, PA 19104 (E-mail: fullers@email.chop.edu).

J Thorac Cardiovasc Surg 2022;164:e523-4

$0022-5223 / \$ 36.00$

Copyright (c) 2021 by The American Association for Thoracic Surgery

https://doi.org/10.1016/j.jtcvs.2021.10.017
}

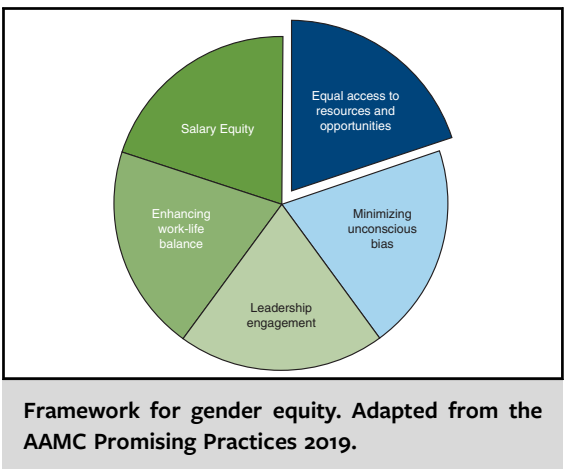

CENTRAL MESSAGE

Women in congenital heart surgery experience bias and harassment. Gender equality is possible via substantive and strategic solutions implemented by invested leaders and supported by male colleagues.

tangible and enduring change. For example, each program should have institutional resources for women faculty and a confidential liaison responsible for biasrelated issues with ongoing training and leadership support. $^{2,3}$ Leaders should develop clear models for advancement in which career customization is possible with development of roles that reward mentorship, innovation, teaching, administrative responsibilities, and program representation. ${ }^{4}$

Per the 2019 Association of American Medical Colleges salary equity report, women cardiothoracic surgeons earned $35 \%$ less than men. ${ }^{5}$ A gender wage gap analysis is a first step to establish salary equity and parity. ${ }^{6}$ Clear scales for a compensation structure based on professional contributions should be developed and shared. Contemporary and innovative work practices emphasizing physician health and wellness with attention to maternity leave, flexible workplace policies, and flex scheduling should be developed. By adopting policies and practices that allow women to have productive and sustained careers with family-supportive practices, we can create a culture in which women feel valued and thrive without fear of penalty or stigma. ${ }^{3}$ Routine needs assessments of faculty can identify emerging issues and 
stimulate conversations surrounding improvements in the workplace. Furthermore, engagement across faculty inspires empowerment-and feeling heard leads to an improvement in culture.

More than $82 \%$ of the women surveyed serve as mentors to other women aspiring to be CHSs. ${ }^{1}$ Hence, women have the potential to comprise a significant portion of the future workforce. The time to establish unbiased practices and modify behaviors to create a more accepting and equally balanced surgical society is now. By increasing inclusivity in medicine, we establish uniformly fair promotion practices, compensation, and leadership. By diversifying the health care workforce, providers better represent their patients. And we recruit the best and brightest.

\section{References}

1. Sinha R, Herbst KW, Romano JC. Status of women in congenital heart surgery: results from a national survey. J Thorac Cardiovasc Surg. 2022;164:e513-22.

2. Lautenberger DM, Dander VM. The State of Women in Academic Medicine 20182019: Exploring Pathways to Equity. Association of American Medical Colleges. Accessed November 2, 2021. Available at: https://www.aamc.org/data-reports/ data/2018-2019-state-women-academic-medicine-exploring-pathways-equity

3. Wai PY, Dandar V, Radosevich DM, Brubaker L, Kuo PC. Retention of surgical specialists in academic medicine in the United States. J Am Coll Surg. 2014;219:31-44.

4. Pati S, Reum J, Conant E, Tuton LW, Scott P, Abbuhl S, et al. Tradition meets innovation: transforming academic medical culture at the University of Pennsylvania's Perelman School of Medicine. Acad Med. 2013;88:461-4.

5. Dander VM, Lautenberger DM, Garrison GE. Promising Practices for Understanding and Addressing Salary Equity at U.S. Medical Schools. Association of American Medical Colleges. Accessed November 2, 2021. Available at: https://www. aamc.org/data-reports/faculty-institutions/report/promising-practices-understand ing-and-addressing-salary-equity-us-medical-schools

6. Whaley CM, Arnold DR, Gross N, Jena AB. Practice composition and sex differences in physician income: observational study. BMJ. 2020;370:m2588.
See Article page e513.

\section{Commentary: Of pipelines, ceilings, and monsters}

\section{R. D. B. Jaquiss, MD}

Most of us negotiate the trials of life by overcoming some measure of self-doubt with a larger element of confidence and positive self-regard. Congenital heart surgeons are quite accomplished in this effort, perhaps even pathologically so. In our high-stakes arena of practice, a positive self-image is empowering in times of challenge, when we must move forward despite obstacles that might seem daunting to others. However, when a critical and negative assessment of ourselves or our performance is produced, it may be devastating. This is particularly true if it confirms intuitions that may have been tamped down and hidden, feelings that we are not quite so wonderful. Thus, after a careful reading of the report by Sinha and

\footnotetext{
From the Department of Thoracic and Cardiovascular Surgery, Children's Health System of Texas and UT Southwestern Medical Center, Dallas, Tex.

Disclosures: The author reported no conflicts of interest.

The Journal policy requires editors and reviewers to disclose conflicts of interest and to decline handling or reviewing manuscripts for which they may have a conflict of interest. The editors and reviewers of this article have no conflicts of interest.

Received for publication Oct 6, 2021; revisions received Oct 6, 2021; accepted for publication Oct 7, 2021; available ahead of print Oct 12, 2021.

Address for reprints: R. D. B. Jaquiss, MD, Department of Thoracic and Cardiovascular Surgery, Children's Health System of Texas and UT Southwestern Medical Center, 1935 Medical District Dr, Dallas, TX 75235 (E-mail: Robert.jaquiss@ utsouthwestern.edu).

J Thorac Cardiovasc Surg 2022;164:e524-5

0022-5223/\$36.00

Copyright (c) 2021 by The American Association for Thoracic Surgery

https://doi.org/10.1016/j.jtcvs.2021.10.011
}

Check for updates

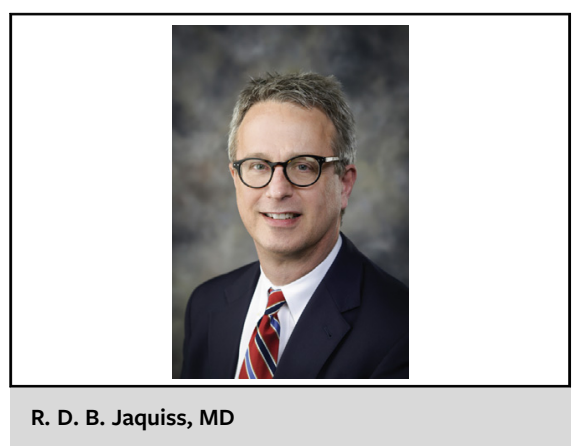

CENTRAL MESSAGE

Women are systematically

excluded from the practice of

congenital heart surgery by

dissuasion, undercompensation,

and the maintenance of a hostile

work environment. Change is

urgently required.

colleagues, ${ }^{1}$ I am embarrassed and ashamed of my contributions to a status quo that is so clearly unjust and misogynistic.

The study by Sinha and colleagues ${ }^{1}$ portrays themes by now familiar to any reader who has not recently emerged from a coma. An important example is the so-called "leaky pipeline." At the intake of the pipeline is a college graduating class that is at least $50 \%$ female. This number declines 